\title{
10 minutes with Professor Amiran Gamkrelidze, Director General of the National Center for Disease Control and Public Health of Georgia
}
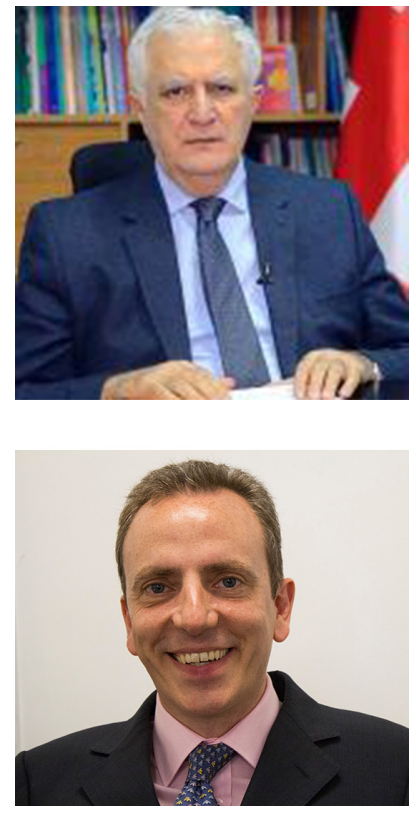

\section{INTRODUCTION}

In this brief interview Professor Amiran Gamkrelidze, Director General of the National Center for Disease Control and Public Health, explains his leadership role in the pandemic response and shares what he has learnt so far.

\section{WHAT ARE THE KEY LEADERSHIP MESSAGES YOU WANT TO GET OUT TO THE BMJ LEADER READERSHIP?}

Thus far, Georgia has performed well in its response to the COVID-19 pandemic. $^{1}$ The number of cases has remained relatively low and the health sector has managed to keep the outbreak under control. The government started preparing early and has maintained a good level of public confidence in its activities. This is likely to be due to a number of reasons. The response has been multisectoral; the public health community has led from the front; and the health system has been strengthening its human resources for health for a number of years. Georgia had a multisectoral response involving the health sector but also the ministries of education, finance, foreign affairs and border security. Georgia is a relatively small country, but it has managed to succeed in slowing the spread and managing the infection throughout the country. The multisectoral response is a large part of the reason for this. I would add three main principles that are leitmotifs in my work style, particularly during this pandemic: teamwork and good coordination, ensuring an intersectoral response, active monitoring of national and international tendencies and using them for the notification of our government about timely measures.

\section{TELL US A LITTLE BIT ABOUT YOUR LEADERSHIP ROLE AND} HOW IT IS CHANGING AS A RESULT OF THE PANDEMIC?

Situated at the strategically important crossroads where Europe meets Asia, Georgia has a unique and ancient cultural heritage

\section{Biographies}

Professor Amiran Gamkrelidze has been Director General of the National Center for Disease Control and Public Health of Georgia since 2013. He is a Professor of the School of Sciences and Public Health at the University of Georgia and a Visiting Professor in Global Health at the Tromso University. He is also a Visiting Professor at the International Public Health School of the Tbilisi State Medical University. He has been a scientific advisor at the Center of Allergology and Immunology since 2005 and a Chair of Allergy and Immunology Alliance since 1990. In 2005-2013, Dr. Gamkrelidze worked as a Country Program Coordinator for the WHO Country office in Georgia; in 2001-2004, he was a Minister of Labour, Health and Social Affairs.

Dr Kieran Walsh is Clinical Director at BMJ. He is the clinical lead of the medical education and clinical decision support resources at BMJ and also Adjunct Associate Professor in Teaching and Research at Monash University.

and is famed for its traditions of hospitality and cuisine. The population of Georgia is 3726000 and life expectancy at birth is 74.1 (male-69.8, female-78.4). Georgia is striving for European and Euro-Atlantic integration, as political priorities for the country's security vision. The National Center for Disease Control (NCDC) and Public Health of Georgia is the leading public health institution in the country, whose mission is the protection and improvement of the health of Georgia's population through scientific evidence-based prevention of diseases. It is also responsible for preparing for and responding to threats to public health in a timely way. The NCDC strategic priorities are as follows: reduction of morbidity and mortality caused by communicable and non-communicable diseases; assessment and reduction of environmental hazards and behavioural risk factors and so improvement in population health; development of fundamental and applied biomedical and biotechnological scientific research; strengthening of preparedness capacities for a rapid and effective response to public health threats; development of electronic information systems; and the development of better public healthcare system management.

During the COVID-19 pandemic, the NCDC has been one of the key players in the response. Most if the resources of the NCDC were applied to the response measures. During the pandemic, the organisation has been responsible for the monitoring and surveillance of the infection, early laboratory detection and diagnostics, contact tracing, forecasting, daily reporting to the government and awareness raising in the population through the mass media.

As a Director General of the NCDC and Public Health of Georgia, I felt a great responsibility from the very beginning for my country's citizens. This started in January 2020 and continued during the pandemic. The NCDC has been playing a key role in managing the epidemic in the country. This has been in terms of surveillance, contact tracing, laboratory reference diagnostics, testing, electronic data collection and analysis, provision of recommendations to the Government Coordination 
Board, and driving public awareness and communication. The responsibilities are high and commitments are significant, and therefore it has meant a lot of work every day to oversee and supervise the whole process. As leader of the NCDC team, I would like to emphasise that I am very proud of my staff's dedication and professionalism and attitude to the work they have been doing during these challenging times. However, the success of the country is also down to the other government bodies which are part of the Government Coordination Board. This is led by the Prime Minister of Georgia.

\section{WHAT EVENTS IN YOUR PAST EXPERIENCE ARE MOST INFORMING YOUR LEADERSHIP IN THIS PANDEMIC?}

During my professional career at the top management level in the healthcare system, I have had to deal with the management of a number of epidemics. These include outbreaks of diphtheria, amoebiasis and measles. I have also been part of the polio eradication programme. In the past 5 years, I have worked with the rest of the staff in the NCDC to strengthen the health system in Georgia. Strengthening human resources has been a large part of this. We have worked with BMJ for 4 years to develop programmes of continuous professional development for healthcare professionals in clinical and non-clinical fields. This gave us experience to prepare. Providing online learning resources for primary care doctors-in both English and Georgian-has helped. Human resources for health are a crucial component of health reforms. Providing content that is continually updated is also important. The COVID-19 virus is newit is still only 6 months old. Everyday there is something new and so it is vital that we have access to BMJ's resources and can share new evidence on diagnosis, epidemiology, contact tracing, rapid surveillance and standards for infection control. Having evidence-based knowledge is most important. The lessons learnt from previous epidemics were to realise that it is not the function of just the healthcare system to respond. The response should involve good intersectoral coordination. The country should have well-functioning early detection and surveillance systems and it should gradually develop digitalisation of these systems to enable timely response measures. It is very important to share the evidence-based experiences of the international leading public health institutions and adapt them to one's local context.

\section{WHAT ARE YOU FINDING THE BIGGEST CHALLENGES?}

We are very dependent on the behavioural factors of the general population. Thus far, the people of Georgia have responded very well, but we also need to be prepared for a second wave if it occurs and to be ready to take further preventive measures. The healthcare system in Georgia could be stronger, but we are making progress. We made good use of time in January and February in preparation for the pandemic. We activated operations in January and since then we have been training doctors in a wide range of things-including COVID-19 and infection control. State capacity is most important. The state plays a leading role in outbreaks like this. The Ministry of Health has played an important role in coordinating activities between the public and private sectors. The capacity of the state hospitals has managed well so far in the first wave. Laboratory and testing capacity is also important. There are now 19 laboratories in Georgia that are operational for diagnostic purposes in COVID-19. The other great challenge is that COVID-19 has until recently been an unknown viral infection and so we still know very little about the specific problems that it can cause.

\section{ANY PARTICULAR SURPRISES?}

I was very pleased to see that we managed to persuade the Georgian population to follow the recommendations on public safety, social distancing and hygiene, which came as a good surprise. We have been providing public health information on a daily basis through the mass media-especially in the strict restriction period of the pandemic. Largely the public have cooperated well. I think that this comes down to trust in the health authorities. We have tried to maintain that trust by ensuring that our communications are open and transparent and evidence based. This was difficult during celebrations at Easter which are most important to the Georgian people. But there has been good solidarity in society. My colleagues believed that by standing together we would be able to beat the virus. Also, the Government Coordination Board worked very well. It implemented timely measures regarding the banning of air flights and the suspension of education.

\section{ARE YOU SEEING ANY BEHAVIOURS FROM COLLEAGUES THAT ENCOURAGE OR INSPIRE YOU?}

As I have mentioned, I am proud of my team's complete dedication to the work and their high sense of responsibility. They all have their own important roles. We have also established a COVID-19 group who are in contact 24/7 sharing information among the staff. Also, we hired a number of young volunteerstheir assistance to the team has been extremely valuable. All of these things give me and my team great encouragement and inspiration.

\section{HOW ARE YOU MAINTAINING KINDNESS AND COMPASSION?}

At all my press conferences, I start by expressing my sincere gratitude to the citizens of Georgia, the Government Coordination Board, my colleagues and my staff.

\section{ARE THERE ANY IDEAS OR READINGS THAT YOU FIND HELPFUL, FOR INSPIRATION AND SUPPORT, WHICH YOU WOULD RECOMMEND TO OTHERS?}

Professionalism and teamwork are the main factors of all success. In the case of Georgia, the teamwork and immediate actions at the multisectoral level were productive and were proved to be justified. During the whole time, we have had intense communication with partnering international countries. We conducted teleconferences and webinars with these countries. The NCDC continually monitored the best practices of leading world health institutions: like WHO, Public Health England, BMJ, ECDC, US CDC, Chinese CDC, and Government of the Republic of Korea, the Robert Koch Institute and the Bunderswehr Institute of Microbiology. We incorporated best practices from these into our fight against COVID-19. The public health community in Georgia led the response to COVID-19 and this has helped the country to do well in the first phase. The government and the opposition listened to the professionals and followed their recommendations. Most decisions were based on public health recommendations. We all should realise well that COVID-19 will not disappear tomorrow, the day after tomorrow or even by the end of the year. We will need to learn to cohabitate with it. I believe that effective treatment and vaccination will be developed, and these will ease the situation. However, until then, the population of the world must follow preventive measures: such as social distancing and wearing face masks. COVID-19 will change the world; it will change the principles of communication among states, people and populations (eg, more distance learning and online conferences). The pandemic is not just a 


\section{0 minutes with...}

challenge for one country: the whole world must unite with all its analytic and research capacity to defeat the virus.

\section{WHAT ARE YOU LOOKING FOR FROM YOUR LEADERS?}

I am looking for leaders who can cooperate and manage coordination across different sectors. We need leaders who have the ability to see and solve a problem and who can help coordinate our capacity. This will ultimately slow the spread of the virus and eventually halt the pandemic with minimal losses.

\section{Amiran Gamkrelidze, ${ }^{1}$ Kieran Walsh ${ }^{2}$ \\ NCDC, Tbilisi, Georgia \\ ${ }^{2}$ Global Health Team, BMJ, London, UK}

Correspondence to Dr Kieran Walsh, BMJ, London, UK; kmwalsh@bmj.com

Contributors Both authors made substantial contributions to the conception or design of the work, revised it critically for important intellectual content, approve the final version and agree to be accountable for all aspects of the work in ensuring that questions related to the accuracy or integrity of any part of the work are appropriately investigated and resolved.

Funding The authors have not declared a specific grant for this research from any funding agency in the public, commercial or not-for-profit sectors.
Competing interests $\mathrm{KW}$ works for BMJ which provides clinical decision support and e-learning resources to healthcare professionals in the field of infectious diseases.

Patient consent for publication Not required.

Provenance and peer review Not commissioned; internally peer reviewed.

Data availability statement No data are available.

(C) Author(s) (or their employer(s)) 2021. No commercial re-use. See rights and permissions. Published by BMJ.

$$
\text { Check for updates }
$$

To cite: Gamkrelidze A, Walsh K. BMJ Leader 2021;5:72-74.

Received 30 June 2020

Revised 10 July 2020

Accepted 13 July 2020

Published Online First 12 September 2020

BMJ Leader 2021:5:72-74.

doi:10.1136/leader-2020-000328

\section{REFERENCE}

1 . Available: https://eurasianet.org/georgia-gets-rare-plaudits-for-coronavirus-response 